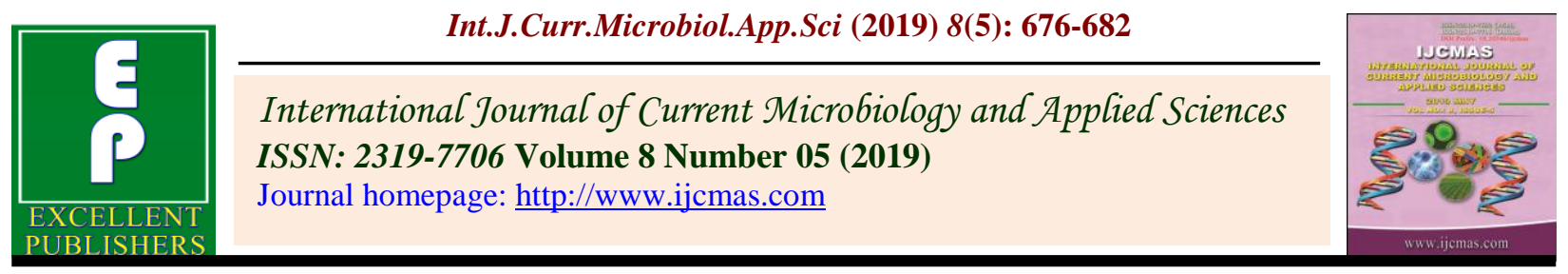

Original Research Article https://doi.org/10.20546/ijcmas.2019.805.079

\title{
Assessment of the Traction Characteristics of a Tractor Running with Diesel-Biogas Fuel
}

\author{
T.M. Mahtem, A.M. Tesfit and L.B. JoeJoe* \\ Department of Agricultural Engineering, Hamelmalo Agricultural College, Eritrea \\ *Corresponding author
}

\section{A B S T R A C T}

Keywords

Traction

characteristics,

Specific fuel

consumption,

Diesel-biogas,

Effective power,

Torque

Article Info

Accepted:

10 April 2019

Available Online:

10 May 2019
Evaluating tractor's capacity and identifying the best working modes are basic and profound phases to fully exploit and make wise and rational combinations of traction vehicles and various agricultural and industrial implements. What goes parallel with this is the question of energy sources. This paper aimed to assess the use of diesel-biogas fuel and assess its traction characteristics. As a result, the characteristic curves of both diesel alone and diesel-biogas tractors show similar characteristics of $45.7 \mathrm{~kW}$ power, at a speed of $2.7 \mathrm{~m} / \mathrm{s}$, and traction force of $17 \mathrm{kN}$, with the exceptional difference in the quantity of specific fuel consumption that is $353.2 \mathrm{~g} / \mathrm{kWh}$ and $304.7 \mathrm{~g} / \mathrm{kWh}$ for diesel and diesel-biogas fuels respectively.

\section{Introduction}

A tractor is a farm vehicle or a farm power unit primarily meant for performing agricultural activities such as tillage, sowing, planting, land leveling, transportation and others, providing high tractive force or torque at low speed. It can be stated that, a tractor is a means by which stored chemical energy is changed into mechanical energy so that a useful work is performed. Thus it involves the transfer of energy from one kind into another. However, during the conversion process, a significant amount of the stored energy is lost as engine transforms chemical energy into mechanical energy. Additionally, losses occur through the drive train and finally through the tractive device. About $20 \%$ to $55 \%$ of the available tractor energy is also wasted at the tractive device/soil interface (Zoz and Grisso, 2003).

Traction or pull force is not only affected by the power losses through the engine to the drive train but also depends on the interaction of the drive wheels and soil. The interactions may be between hard wheels and hard surfaces, hard wheels and soft surfaces, soft wheels and hard surfaces, soft wheels and soft surfaces and belt or chain drives and the soil 
surfaces. These different interactions affect the overall tractive effort and performance of the tractor by affecting the travel speed, torque and power output.

Traction characteristic is a package that represents the relationship between tractive force, speed of movement, specific fuel consumption and speed of rotation of the crankshaft and other factors. A traction characteristic is a basis for the development of energy balance of an automobile, tractor or any other farm machinery.

\section{Materials and Methods}

The primary goal of this study is to evaluate the traction characteristics of a tractor engine running with diesel-biogas fuel. However knowing and selection of the efficient dual fuel proportion stands to be first and basic step. Moreover, as long as emphasizing only on the characteristics of diesel-biogas powered tractor is not sufficient, as a comparison benchmark the traction characteristics of diesel powered tractor was performed.

\section{Section 1: Determination of best diesel- methane proportion}

A certain set of procedures which focus on the thermodynamic process of all four strokes of an internal combustion engine were followed. The procedures show how indicating parameters like specific fuel consumption, engine efficiency and power output change in the entire combustion process using particular dual fuel proportion. Though the full and detailed analysis of the processes is out of the scope of this study main and selected parameters and methods used in defining the best diesel methane combination have been summarized below.

At the beginning of the procedure the turbocharger pressure and temperature were computed using the expressions given by (Kolchin and Demidov, 1984) and (Diyachenko, 2009). The next important parameters, the maximum temperature and pressure at the end of compression process (Klaus, 1988), were expressed as a function of net fuel calorific value, amount of air needed for complete combustion (kuracov et al., 2013) and both temperature and pressure at the end of compression (Kirillin et al., 1983).

In the expansion process, the pressure and temperature at the end of compression, the temperature of exhaust gases related with the degree of subsequent expansion, and other basic system indicators such as estimated mean pressure, indicated power, efficiency and specific indicated fuel consumption as a function of cycle completeness coefficient are considered (Kurasov et al., 2013). Finally to reach the goal of setting the required input parameters for the processing of traction characteristics, taking the mechanical efficiency as 0.90 (Kolchin and Demidov, 1984) the specific fuel consumption, efficiency and effective power were computed.

\section{Section 2: Traction characteristics}

Main parameters on which tractor's traction performance depend are: weight, transmission ratios (travel speeds) and engine power. These parameters are found by the tractor traction assessment. In this study, the traction characteristics of a 4500kgtractor BELARUS923.3, having four cylinder Diesel engine D$245.5 \mathrm{C} 2$, maximum turning moment $451 \mathrm{Nm}$, four wheel drive $70 \mathrm{~kW}$ power and $18 \mathrm{kN}$ nominal tractive force are determined with their respective formulas. For calculations, the initial data are given.

The parameters required to get the traction characteristics of the tractor under investigation are outlined below. 
The operational weight of the tractor $\left(\mathrm{G}_{\mathrm{Tp}}\right)$ is given by the formula:

$G_{\text {тр }}=\frac{P_{\text {кр н }}}{\lambda_{\kappa} \varphi_{\kappa}-f_{\text {к }}}$

Where $\mathrm{P}_{\text {крн }}$ : nominal tractive force $(\mathrm{kN}), \lambda_{\mathrm{K}}$ : load factor of driving wheels, $\varphi_{\kappa}$ : friction coefficient, $\mathrm{f}_{\mathrm{k}}$ : Rolling resistance coefficient. The value of the load factor on the drive wheels of the tractor wheel formula $4 \mathrm{~K} 4 \lambda_{\mathrm{k}}$ is taken as 1 (Kutkov, 2014).

Using the mechanical efficiency of the transmission $\left(n_{\mathrm{Tp}}\right)$ the nominal operating power of the engine follows as

$$
\begin{aligned}
& \eta_{\text {тр }}=\eta_{\mathrm{c}}^{m} \cdot \eta_{\mathrm{\kappa}}^{n}(1-\zeta) \\
& N_{\text {н э }}=\frac{\left(P_{\text {кр н }}+P_{\mathrm{f}}\right) v_{\text {тр н }}}{\eta_{\text {тр }}\left(1-\delta_{\text {н }}\right)} \\
& P_{f}=f_{\mathrm{K}} \cdot G_{T p} \cos \alpha
\end{aligned}
$$

Where $\mathrm{P}_{\mathrm{f}}$ : is the rolling resistance force $(\mathrm{kN})$, $f_{k}$ : coefficient of friction, $\alpha$ : slope of the ground, $\mathrm{V}_{\text {тр.н }}$ : actual tractor speed at nominal tractive force $(\mathrm{m} / \mathrm{s}), \quad \eta_{\text {тр }}$ : transmission mechanical efficiency, $\delta \mathrm{H}$ - allowable slipping at a nominal tractive effort, $\zeta$ - coefficient of energy loss in the transmission at idle move, $\eta_{\mathrm{c}}, \eta_{\mathrm{K}}$ - the efficiency of a cylindrical and conical pair of gears, $m$ and $n$ : the number of cylindrical and bevel gear pairs that are engaged at the same time.

According to the law of a geometric progression, the gear ratio is:

$$
i_{1}=\frac{\omega_{\mathrm{d} \mathrm{H}_{\mathrm{H}}} r_{\mathrm{K}}}{v_{\mathrm{T} 1}}, \quad i_{z}=\frac{\omega_{\mathrm{dH}_{\mathrm{H}}} r_{\mathrm{K}}}{v_{\mathrm{T} z}}
$$

$$
\begin{aligned}
& i_{2}=i_{1} q_{i}, i_{3}=i_{2} q_{i} \ldots i_{z} \\
& \frac{1}{q_{\mathrm{i}}} \leq k_{\mathrm{M}}, K_{M}=\frac{M_{K \max }}{M_{K H}}
\end{aligned}
$$

$$
M_{\text {к н }}=\frac{N_{\text {н э }}}{\omega_{\text {dн }_{\text {н }}}}
$$

Where i: gear ratio, $\omega_{\mathrm{d}}$ : crankshaft angular velocity, $\mathrm{r}_{\mathrm{k}}$ : kinematic wheel radius, $\omega_{\mathrm{dH}}$ : nominal crankshaft angular velocity, $\mathrm{V}_{\mathrm{T}}$ : theoretical speed, $\mathrm{q}_{\mathrm{i}}$ : denominator of the geometric progression of the speed of the transmission, $\mathrm{K}_{\mathrm{M}}$ : coefficient of torque adaptability, $\mathrm{M}_{\mathrm{kmax}}$ : maximum torque, $\mathrm{M}_{\mathrm{kH}}$ : nominal torque.

The effective engine power $\left(\mathrm{N}_{\mathrm{e}}\right)$, hourly fuel consumption $\left(\mathrm{G}_{\mathrm{T}}\right)$ and the value of the angular velocity $\left(\omega_{M}\right)$ of the crankshaft of the engine corresponding to the maximum torque are worked out as follows.

$$
\begin{aligned}
& N_{\mathrm{e}}=10^{-3} M_{\mathrm{e}} \omega_{\mathrm{d}}(9) \\
& G_{\mathrm{T}}=10^{-3} g_{\mathrm{e}} N_{\mathrm{e}}(10) \\
& \omega_{\mathrm{M}}=\omega_{\mathrm{dH}} k_{\omega}(11)
\end{aligned}
$$

Where $\mathrm{k} \omega$ : diesel engine adaptability factor.

Traction is the main characteristic of the tractor, which determines its traction and energy performance. Calculations of the tangential thrust force $\left(\mathrm{P}_{\mathrm{kp}}\right)$ as a function of torque $(\mathrm{Mk})$, rolling resistance force $\left(\mathrm{P}_{\mathrm{f}}\right)$ and the theoretical speed of the tractor $\left(v_{\mathrm{T}}\right)$ as a function of angular velocity $\left(\omega_{\mathrm{d}}\right)$ is done.

$P_{\mathrm{K}}=\frac{M_{\mathrm{\kappa}} i_{\text {тр }} \eta_{\mathrm{Tp}}}{r_{\mathrm{d}}}$ 


$$
\begin{aligned}
& P_{\text {кр }}=P_{\mathrm{K}}-P_{f} \\
& v_{\mathrm{T}}=\frac{\omega_{\mathrm{d}} r_{\mathrm{K}}}{i_{\mathrm{Tp}}}
\end{aligned}
$$

The slip $(\delta)$ of the tractor tires depends mainly on the soil background, the type and parameters of the wheels and the weight of the tractor. In this process the slip has been defined as a function of tractor's theoretical and operational velocity $\left(\mathrm{V}_{\mathrm{Tp}}\right)$

$$
\begin{aligned}
& v_{\text {тр }}=v_{\mathrm{T}}(1-\delta) \\
& N_{\text {кр }}=P_{\text {кр }} v_{\text {тр }}
\end{aligned}
$$

The specific operational fuel consumption is computed in relation with the drawbar power $\left(\mathrm{N}_{\mathrm{kp}}\right)$ and hourly fuel consumption $\left(\mathrm{G}_{\mathrm{T}}\right)$.

$g_{\text {кр }}=\frac{G_{\text {т }}}{N_{\text {кр }}}$

\section{Results and Discussion}

To determine the best diesel-biogas proportions putting the concept referenced in the methodology part and with the help of Excel sheet a detailed analysis was performed. In the simulation as the temperature of the residual and exhaust gases were kept within the range $600-900 \mathrm{~K}$ (Brandon, 2015), the indicating parameters namely specific fuel consumption, efficiency and effective power required for the development of traction characteristics were figured out and have been presented in the graph below. In the analysis the effective power resulting from different diesel-biogas proportions was targeted to be approximately equal to rated power of the engine $(70 \mathrm{~kW})$. The graph shows different proportions of diesel and biogas $\left(98 \% \mathrm{CH}_{4}\right)$ along with their specific fuel consumption and resulting efficiencies. As it can be seen from the graph as the methane proportion increases the efficiency increases and the specific fuel consumption decreases significantly up to $75 \%$ biogas and $25 \%$ diesel. At this point, the engine efficiency is at its maximum (43\%) and the specific fuel consumption is its minimum value. However beyond this point the graph shows a decrease in efficiency and an increase in fuel consumption. Hence as a basis for the traction computation the $75 \%$ biogas and $25 \%$ diesel proportion with a specific fuel consumption of $195 \mathrm{~g} / \mathrm{kWh}$ was selected (Fig. 1).

Using the methods mentioned in the methodology section, the engine torque, effective power, hourly and specific fuel consumptions were examined using an Excel sheet simulator, and the results have been presented in the graphs below. The simulator was made to work firstly with only diesel and secondly with $25 \%$ diesel and $75 \%$ biogas fuels. In Figure 2 (a) the maximum values of torque is $372.3 \mathrm{Nm}$, the hourly and specific fuel consumptions are $15.7 \mathrm{~kg} / \mathrm{h}$ and $225 \mathrm{~g} / \mathrm{kWh}$ respectively for an effective power of $70 \mathrm{~kW}$. Whereas, in Figure 2(b) for same values of torque and effective power, the hourly and specific fuel consumptions are $13.5 \mathrm{~kg} / \mathrm{h}$ and $195 \mathrm{~g} / \mathrm{kWh}$. The regulated engine operation modes in both cases where engine runs with only diesel and with $25 \%$ diesel and $75 \%$ biogas show similar characteristics, though the gravimetric fuel consumption differs significantly.

\section{Traction characteristics}

The dependencies of effective power $\left(\mathrm{N}_{\mathrm{e}}\right)$, specific fuel consumption $\left(\mathrm{g}_{\mathrm{e}}\right)$, operational speed $(\mathrm{V})$, slip $(\delta)$ and the working efficiency on the tractive force $\left(\mathrm{P}_{\mathrm{kp}}\right)$ in different gears of a tractor are regarded as traction characteristics. The traction characteristics 
make it possible to evaluate the dynamic and economic indexes of a tractor and is reached either by calculation of the theoretical traction characteristic or by field tests. The traction characteristics depend on the power of the engine, the type of propulsion device, the weight of the vehicle, and the physicomechanical properties of the surface over which the vehicle is moving. Traction characteristics are also used to make rational combinations of traction vehicles and various agricultural and industrial implements. In this study the theoretical traction characteristics of diesel and diesel-biogas powered BELARUS-
923.3 tractor in seven gears was compared. The theoretical characteristic curves were developed with the help of Excel simulation based on the expressions mentioned in the methodology section. Their respective graphical characteristics are explained below.

In figure 3 the characteristic curve show that the tractor can efficiently be operated in the fourth gear. In this gear, the tractor operates at a speed of $2.7 \mathrm{~m} / \mathrm{s}$ with a power of $45 \mathrm{~kW}$, a tractive force of $17 \mathrm{kN}$ consuming $351.6 \mathrm{~g} / \mathrm{kWh}$ of diesel and shows a maximum efficiency of $63.7 \%$.

Fig.1 Efficiency and Specific fuel consumption of different diesel-biogas proportions

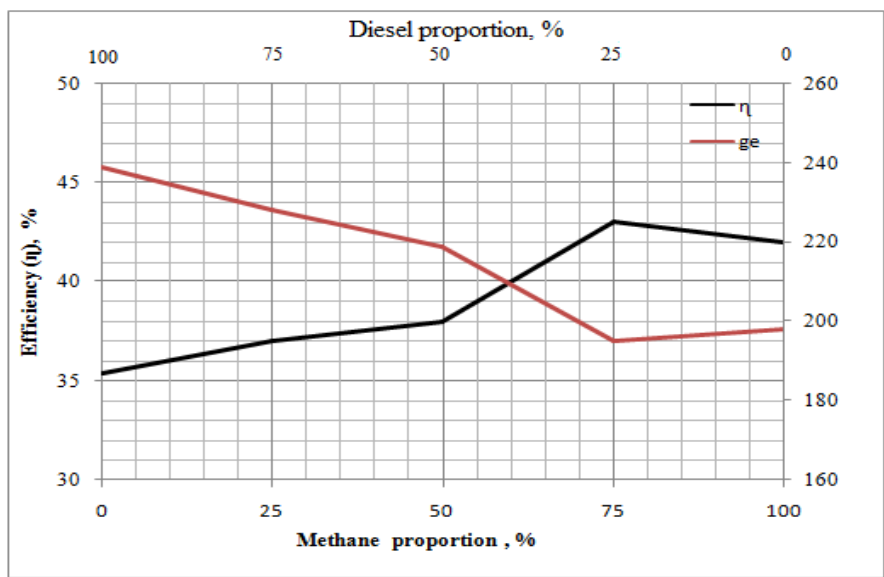

Fig.2 Power $\left(\mathrm{N}_{\mathrm{e}}\right)$, torque $\left(\mathrm{M}_{\mathrm{k}}\right)$, hourly $\left(\mathrm{G}_{\mathrm{T}}\right)$ and specific $\left(\mathrm{g}_{\mathrm{e}}\right)$ fuel consumption versus angular velocity of (a) $100 \%$ diesel; (b) $25 \%$ diesel and $75 \%$ biogas proportions

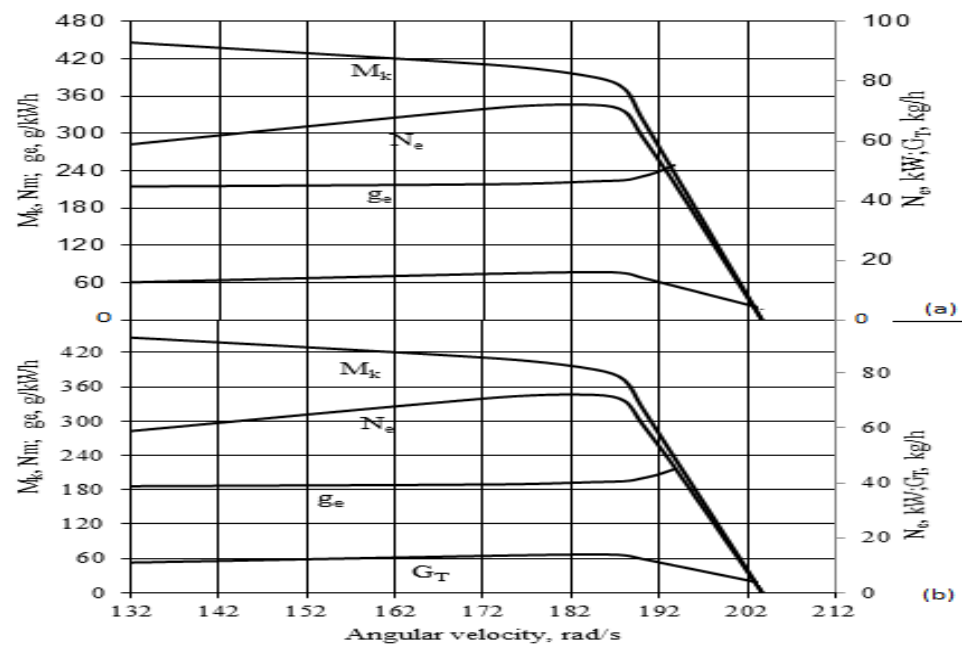


Fig.3 Diesel traction characteristic curves

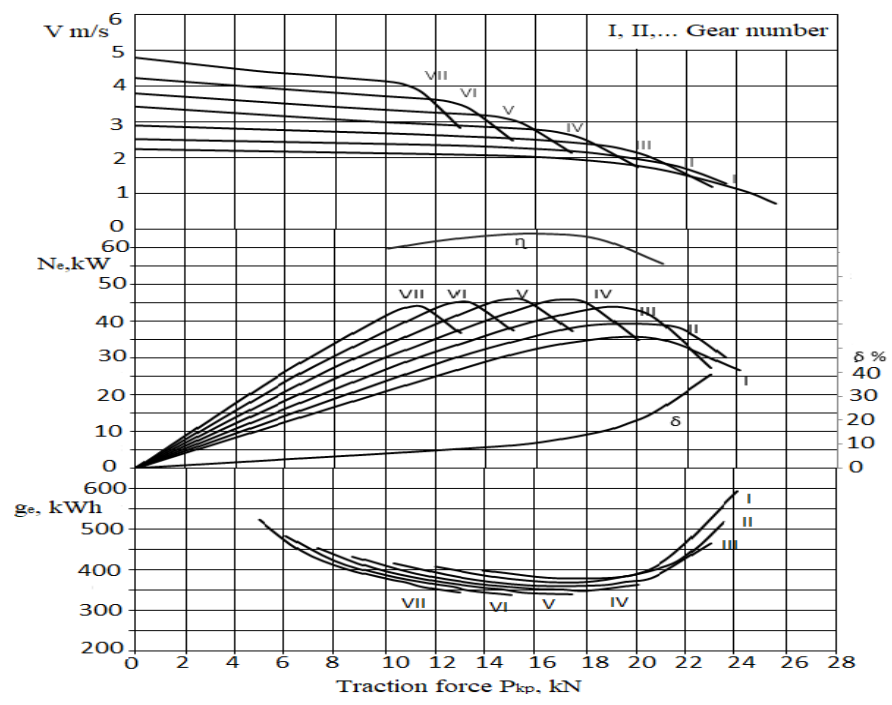

Fig.4 Diesel-biogas traction characteristic curves

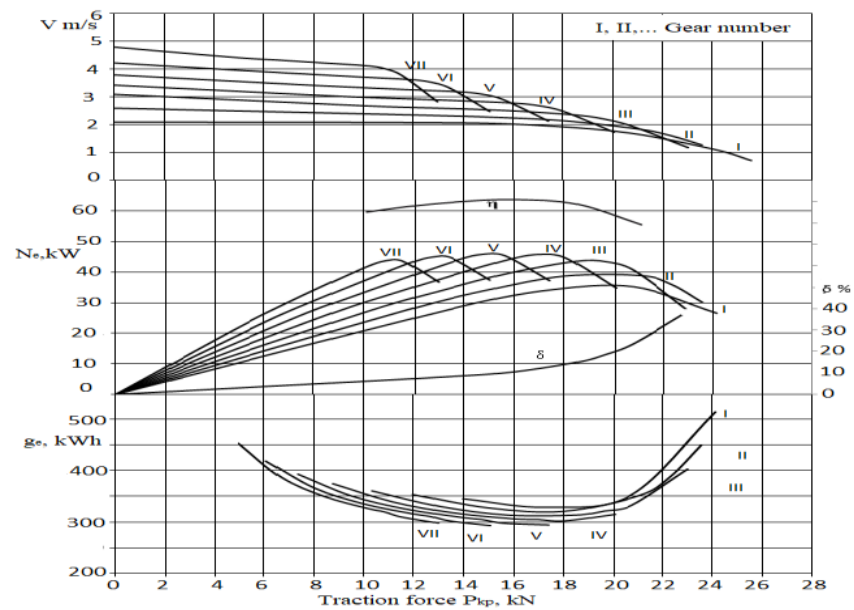

Similarly in figure 4 the group of characteristic curves shows that the tractor can efficiently be operated in the fourth gear, at a speed of $2.7 \mathrm{~m} / \mathrm{s}$ with a power of $45 \mathrm{~kW}$, a tractive force of $17 \mathrm{kN}$ consuming $304.7 \mathrm{~g} / \mathrm{kWh}$ of diesel-biogas fuel and shows similar efficiency. From the above comparison the only noticeable difference is in the specific fuel consumptions.

It is concluded based on the analysis both the regulated engine mode curves and the traction characteristic curves have shown that using either diesel or diesel-biogas fuel results in similar characteristics. Although a noticeable differences occurs in the specific fuel consumption, as far as the unit cost of power is not taken into account, it is not worthy of saying that using diesel-biogas fuel is absolutely economical and advantageous. Nevertheless, it is well known that both burning diesel and production of methane result in adverse effects of greenhouse. Methane contributes about $20 \%$ to the total increase in the greenhouse effect caused by human activities, in other words its greenhouse effect is about 22 times as $\mathrm{CO}_{2}$ (Jørgensen, 2009). Thus, reducing the 
consumption of diesel in one hand and increasing the utilization of methane in the other hand, has a valuable positive impact in the ecological concern.

\section{References}

Brandon, T.T., 2015. The characterization two-sage ignition effects on late injection low temperature combustion using biodiesel and biodiesel blends. [Doctoral Dissertation]. Texas A\&M University., 2015.

Diyachenko, V.G., 2009. Theory of Internal combustion Engine. Karkov Polytechnic Institute. Kharkov, p. 505. (In Russian).

Jørgensen, P.J., 2009. Biogas - green energy, Faculty of Agricultural Sciences, Aarhus University.

Kirillin, V.A., Sechev, V.V. and Sheyndlin, A. E., 1983. Technical
Thermodynamics, Energoatomizad at. Moscow, p. 409.

Klaus, V.M., 1988. Engines for biogas. Deutsches Zentrum Entwicklungs technologien Gate. Gottingen. P. 132.

Kolchin, A.I., and Demidov, V., 1984. Design of Automotive Engines. Mir Publishers, Moscow, p. 430.

Kurasov, V.C., Duragulenko V. V. and Sidorenko C. M., 2013. Theory of Internal Combustion engine. Kuban State Agrarian University. Krasnadar. P. 86 (In Russian).

Kutkov, G.M., 2014. Tractors and Automobiles, Theoretical and technological properties. Higher Education, Moscow Russia, p. 504. (In Russian).

Zoz, F.M. and Grisso, R. D., 2003. Traction and Tractor performance. ASAE, 2950 Niles Rd., St. Joseph, MI 49085-9659 USA.

\section{How to cite this article:}

Mahtem, T.M., A.M. Tesfit and JoeJoe, L.B. 2019. Assessment of the Traction Characteristics of a Tractor Running with Diesel-Biogas Fuel. Int.J.Curr.Microbiol.App.Sci. 8(05): 676-682. doi: https://doi.org/10.20546/ijcmas.2019.805.079 